JOSÉ SOLÍS OPAZO

ESCUELA DE ARQUITECTURA

FACULTAD DE ARQUITECTURA,

URBANISMO Y PAISAJE

UNIVERSIDAD CENTRAL

SANTIAGO, CHILE

JOSE.SOLIS@UCENTRAL.CL

JOSESOLISOPAZO@GMAIL.COM

\title{
Mal de proyecto. Archivo ficcional y proyectualidad
}

\author{
Ailment of Project. Fictional Archive and Projectuality
}

Resumen. La noción de proyecto, altamente cuestionada a partir de la denominada "muerte del sujeto" dada su inevitable identificación con este último, aparece como un índice de primordial importancia a la hora de repensarla desde las condiciones actuales del arte contemporáneo, sobre todo, desde el modo en que la lógica del archivo ha logrado hegemonizar un importante conjunto de sus prácticas. La pregunta por el "archivo de proyecto" vendría a colocar en juego un supuesto doble agotamiento: el del proyecto, como recurso ético-político fundamental de la modernidad; y el del arte, en tanto puesta en obra de una reflexión por los recursos de representación y significación de los códigos que intentan organizan lo que llamamos "realidad". Archivar la promesa de liberación, lejos de concebirse como un acto de desprendimiento o abandono de esta, constituye una acción necesaria para proteger su irreductibilidad a las condiciones de lo meramente posible.

Palabras clave: archivo, movimiento moderno, proyecto, psicoanálisis, ucronía.

\begin{abstract}
The notion of project, highly questioned from the so-called "dead of the subject" due its inevitable identification with it appears as an index of primary importance when comes to rethink it from the current conditions of contemporary art, above all from the way in which the logic of the archive has achieved to hegemonise a significant group of its practices. The question regarding "archive project" would come to put in play a supposed double exhaustion: on the project, as a fundamental ethic-political resource of modernity; and on art, while staging a reflection by the resources of representations and signification of codes that attempt to organise what we call "reality." To archive the liberation promise, far to be conceived as an act of detachment or neglect, constitutes a necessary action to protect its irreducibility to merely possible conditions.
\end{abstract}

Keywords: archive, modernism, project, psychoanalysis, uchronia.

Fecha de recepción: 30/01/2015

Fecha de aceptación: 12/04/2016

Cómo citar: Solís Opazo, J. (2016). Mal de

proyecto. Archivo ficcional y proyectualidad.

RChD: creación y pensamiento, I(1), 27-36.

DOI: $10.5354 / 0718-2430.2016 .44197$

Revista Chilena de Diseño,

RChD: creación y pensamiento

Universidad de Chile

2016, 1(1)

http://rchd.uchile.cl 


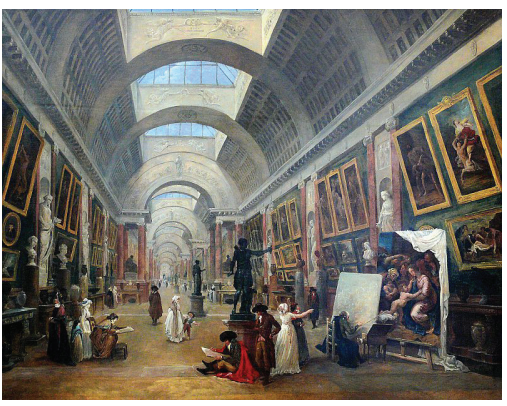

Figura 1. Gran Galería del Louvre. Hubert Robert, 1796. Fuente: <https://commons.wikimedia.org/wiki/ Hubert_Robert\#/media/File:Hubert_Robert_-_Die_ Grand_Galerie_des_Louvre.jpg>

Ante la distinción entre las nociones de arrojamiento (Geworfenheit) y proyecto (Entwurf) dispuestas en SeryTiempo, Heidegger (2002) parece haber tomado una posición poco auspiciosa para esta última. Para el pensador alemán, el proyecto no es de ningún modo una decisión trascendente respecto de la situación existencial en la que, en cada caso, siempre nos encontramos (el ahí del Ser). Al contrario, el proyecto es un ámbito inmanente a la condición de arrojamiento (Geworfenheit), es decir, interior a las posibilidades históricas abiertas por el Ser, entre las cuales el propio proyecto no es más que una entre las demás. La idea de una facticidad insuperable como esta, es bastante tentadora en tiempos donde los sucesos ya no parecen obedecer a decisión alguna, sino más bien a procesos completamente autónomos en su comportamiento, como son la técnica y el mercado.

Frente a esta impotencia, es completamente plausible hablar de la "muerte del proyecto", si este último lo entendemos como el ejercicio de decidir superar las condiciones heredadas en vistas a apostar por algo distinto de lo simplemente presente. Sin embargo, no debemos tomar al pie de la letra este lapidario veredicto. Una alternativa a ello sería asumir el fin del proyecto de manera análoga a como Hegel, por ejemplo, exigía comprender la idea de la "muerte del arte". Como sabemos, Hegel no la concebía como un simple desaparecer total y definitivo de los artistas y de las obras, sino como una progresiva devaluación de su estatura ontológica: para Hegel el arte, en la modernidad, ya no representa más la puesta en obra de lo absoluto, como ocurría en épocas pasadas (Hegel, 1989).

Análogamente, podemos entender la "muerte del proyecto" no como su simple imposibilidad, sino más bien como una drástica contracción de su despliegue.

De la misma manera en que para Adorno - siguiendo a Hegel- el arte ha quedado finalmente reducido a la industria cultural (Adorno, 2005), el proyecto en su concepción moderna, aparentemente no tiene más lugar que en las definiciones académicas del diseño y la arquitectura. No obstante, también podemos considerar lo contrario. Lejos de comprimirse en la autonomía institucional, el arte ha expandido cada vez más sus límites al extremo de disiparse en la propia realidad, como parece ocurrir a través del diseño. De igual manera, hoy en día el proyecto sería la realización concreta de lo que antaño se concebía únicamente en los planos de la ideación ética y estética. En cierto sentido, hoy estaríamos inundados por su presencia en la medida en que toda acción a concretar -científica, económica, política o técnica- debe estar debidamente anticipada por un proyecto.

Más allá de ambas posiciones contrarias, la sentencia hegeliana de la muerte del arte recoge sin duda la idea de un singular agotamiento. Sergio Rojas (2012) observa la evidencia de este fenómeno a propósito de dos obras que fueron presentadas en el Salón parisino en 1796, del pintor Hubert Robert. Mientras en la primera de ellas Robert nos presenta una imagen de la Gran Galería del Louvre (Figura 1), en la otra pintura exhibe el lienzo titulado Ruinas según el cuadro precedente (Figura 2), en donde se aprecia la misma Gran Galería completamente destruida. A este respecto, Rojas nos comenta:

Acaso la ruina del Museo sea precisamente la ruina por antonomasia. Ruina de la memoria, pero de esa memoria que se ha construido como atesoramiento aurático de la ruina: la informada reunión en un espacio institucional de objetos cuyo mundo ya no existe". (Rojas, 2012, p.79) 


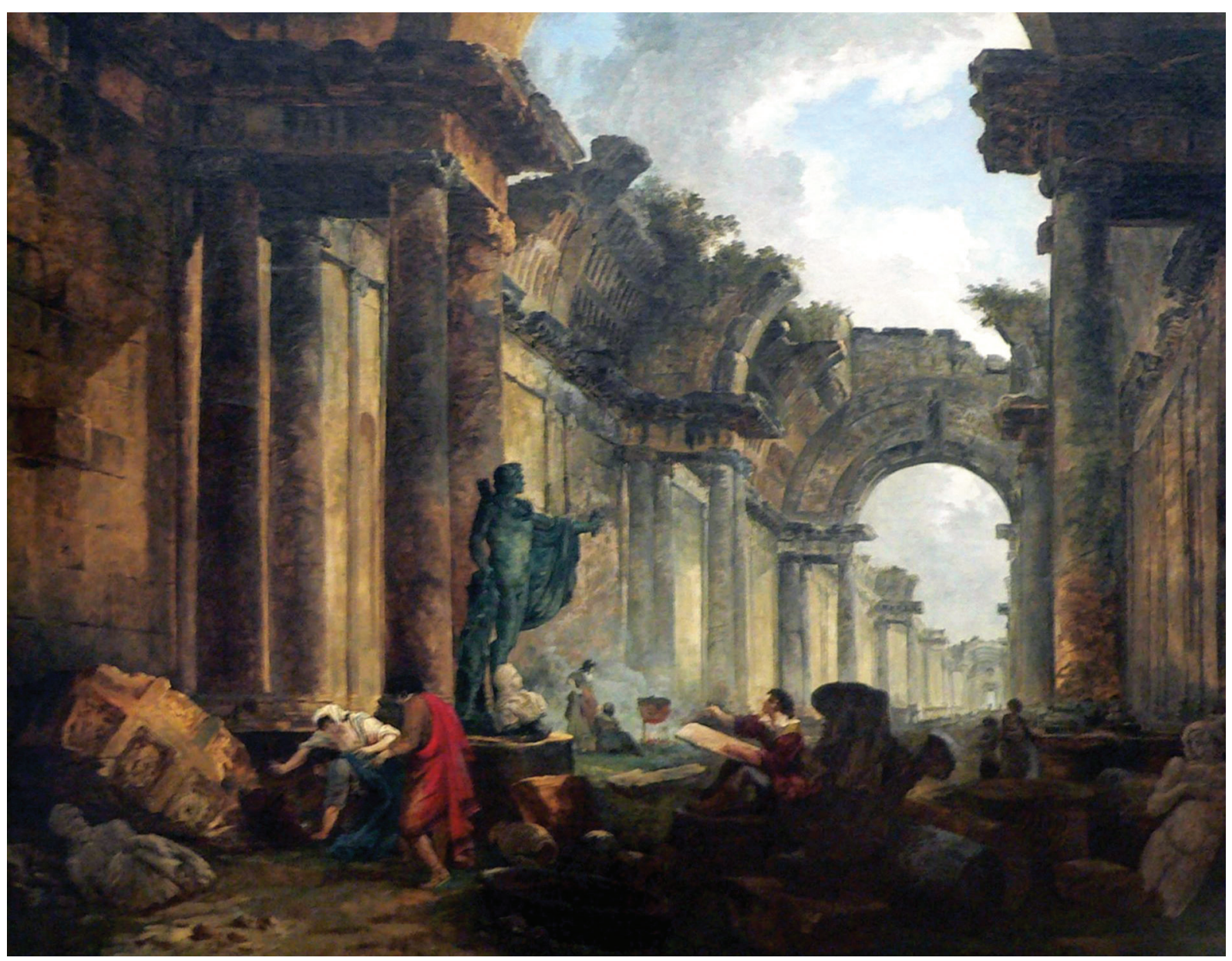

La dificultad para historizar los códigos con los que ordenamos y clasificamos las cosas, es justamente lo que viene a recoger metafóricamente la imagen del Louvre devastado: el presente ya no puede reunir lo acontecido de manera sistemática.

Si todos los dispositivos llamados a organizar los despojos del pasado -como el Museo y la historiografía- se encuentran en situación de ruina, entonces el problema trasunta en cómo hacer de esas ruinas un archivo. En otras palabras, de qué manera volver categorizable, comprensible o historiable el propio arruinamiento de los marcos de comprensión y representación que hemos tenido del pasado.

En definitiva, lo que la pintura de H. Robert nos anticipa, es la tensión entre memoria y arte o, más específicamente, entre archivo y representación. Como bien nos recuerda Jacques Derrida (1997), archivo es un término familiarizado con la voz griega arché que nombra, paralelamente, "comienzo" y "mandato". El concepto de archivo alude al lugar donde las cosas se inician, al tiempo de representar la autoridad y el orden de las mismas.

En cuanto comienzo y autoridad, el archivo implica un domicilio, un lugar (topos) capaz de acoger y atesorar el comienzo (de la ley o nomos), tanto para su aseguramiento como para su "consignación", esto es, la capacidad de reunir en un solo corpus ideal a todos los elementos pretendidamente fundantes
Figura 2. Ruinas según el cuadro precedente. Hubert Robert, 1796.

Fuente: <https://commons.wikimedia.org/wiki/ File:Louvre-peinture-francaise-p1020324.jpg>. 

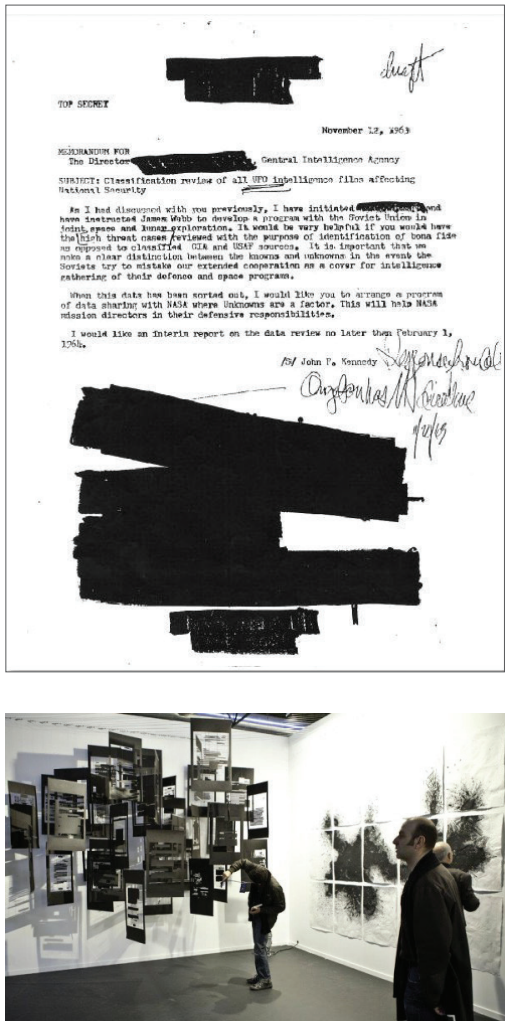

Figura 3. Archivo desclasificado de la CIA. Fuente: <https://codigooculto.com/2016/>. Figura 4. Exposición Minimal Secret. Voluspa Jarpa, Feria de Arte Contemporáneo (Arco) de Madrid 2012.

Fuente: <https://www.flickr.com/photos/ alsaarom/8262459246>

Figura 5. Exposición Minimal Secret. Voluspa Jarpa, Feria de Arte Contemporáneo (Arco) de Madrid 2012.

Fuente: <http://demo.d6.cl/artishock/?p=14277>.

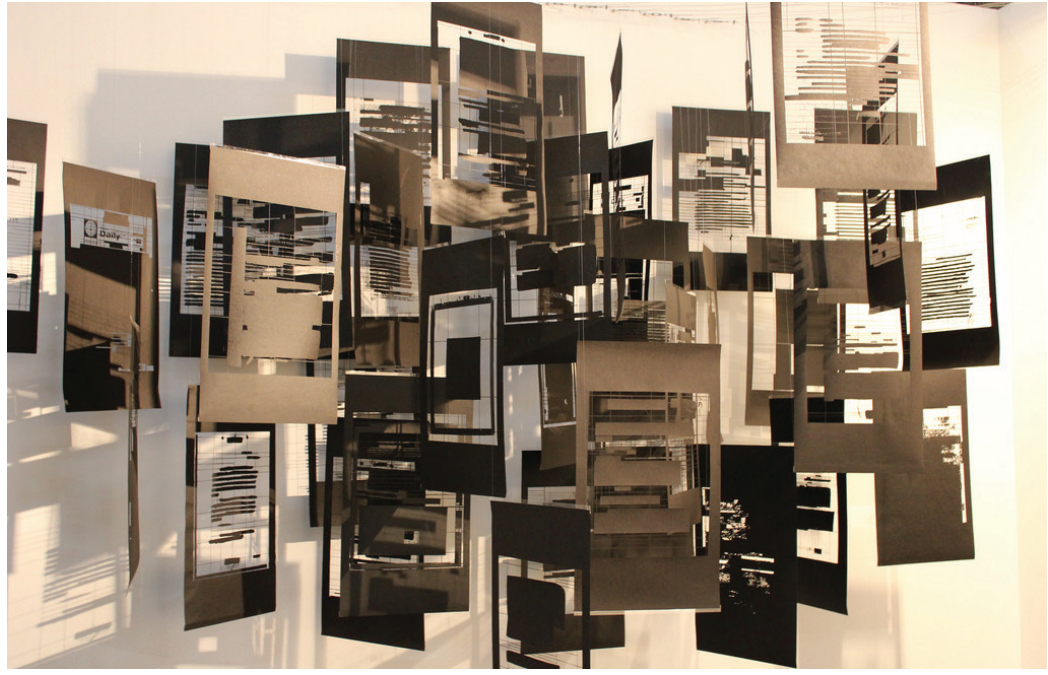

(Derrida, 1997). Pues bien, como nos dice Derrida, no habría posibilidad de archivo sin que este lugar que consigna no involucra, simultáneamente, una técnica de repetición y cierta exterioridad material (a diferencia de la memoria, que es mental). Si lo que debe resguardarse es lo instituido (por el comienzo y la ley), la repetición se torna un recurso elemental, aunque ello implique inevitablemente la inscripción material de lo que debe ser recordado. En cierta medida, la pretendida sobrevivencia física del archivo entraría en contradicción con su propia voluntad de repetición.

En Más allá del principio del placer, Sigmund Freud establece que la compulsión repetitiva de los episodios traumáticos y dolorosos es incomprensible por la vía del principio del placer. Es necesario que exista algo allende de dicho principio que sea capaz de explicar el fenómeno. Ese "más allá" que en cierto modo gobernaría a dicha compulsividad, Freud lo denominará "pulsión de muerte" (Freud, 2001). Básicamente, esta constituiría la tendencia contrapuesta a las pulsiones de vida, cuya propensión es la de devolver a los seres vivos al estado original inorgánico. Su intento por regresar a lo primario hasta un estado anterior al nacimiento, no es otro que la búsqueda de la completa quietud propia de la materia inerte. Esto justificaría la idea de que la autodestrucción sea el límite de dicho proceso regresivo. Pues bien, un aspecto central en la tesis derridiana del archivo es que, precisamente, por estar cifrado bajo la lógica de la repetición -y por tanto, al abrigo de la muerte - involucra una contradicción que atenta contra su misma intención conservadora. Esta condición es la que Derrida denominará "mal de archivo".

El sentido de este "mal", no es otro que la naturaleza contradictoria y autodestructiva que lo constituye. Al igual que la repetición en la que se manifiesta la pulsión de muerte, la permanencia del archivo apunta también a rememorar lo originario. Sin embargo, hay una crucial diferencia con ella. El archivo no busca remontarse a lo anterior inorgánico, sino exactamente a lo contrario: detenerse en aquello que nos ha separado del caos para concentrarse en el comienzo del orden ( $a r c h e ́$ ). De este modo, conviven en el archivo el deseo de regresión-restitución y la autodestrucción. Podríamos enunciar esta paradoja de la siguiente manera: en cuanto incansable deseo de repetición, el archivo es síntoma de muerte al mismo tiempo de intentar exorcizarla a través de la exposición material de su lucha contra la materia. Esto explicaría su naturaleza 


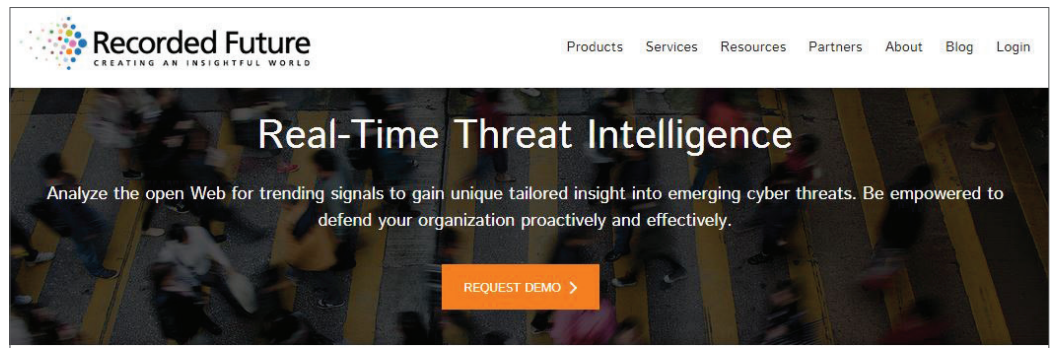

Instantly Analyze 660,511 Sources in 7 Languages

Gain deep visibility into threats impacting you.

We do the hard work for you by automatically collecting and organizing over 650,000 open Web sources to identify actors, new vulnerabilities and emerging threat indicators. Gain deep visibility into your threat landscape by analyzing and visualizing cyber threats, even across foreign languages, with

contradictoria: en el archivo, la muerte - que no es otra cosa que lo impresentable- de algún modo se vuelve presentable.

Otro de los casos ejemplares, esta vez contemporáneo, que Rojas (2012) utiliza para reflexionar en torno a la economía contradictoria del archivo en la era del agotamiento del arte, es el trabajo de la artista chilena Voluspa Jarpa, particularmente su obra titulada Minimal Secret, del año 2012 (Figura 3).

Se trata de una instalación que exhibe un conjunto de páginas provenientes de los archivos desclasificados por la CIA, que contendrían información sobre Chile y otros países latinoamericanos. Junto con esta instalación y a un costado de ella, se encuentra adosada al muro una gran mancha de tinta, que hace alusión a la forma en que estos archivos han sido revelados a la opinión pública: palabras y párrafos completos fueron cuidadosamente tachados para impedir su lectura. Lo interesante que destaca Rojas (2012) al respecto, es que si bien la tachadura reprime el acceso a la información, la puesta en obra de tales archivos coloca en evidencia la imagen misma del borrar como aquello que nos asalta de manera agresiva e interrogante.

Lo que esta obra nos propone es el juego de la visibilidad e invisibilidad propia de toda lógica archivística, su paradójica economía de enunciar lo impresentable "a través de" lo presentable.

En efecto, entendido como depósito que consigna, el archivo tiende a volver invisible al propio objeto que colecciona, es decir, al archivo en cuanto vestigio atesorado. Eso es lo que justificaría su necesaria clasificación. Mientras más grande es el depósito, más invisibles y, por tanto, más necesitados de clasificación se tornan los archivos.

Quizás el ejemplo más elocuente de este efecto es justamente la desmesurada exhibición de los archivos secretos de la CIA por parte de la organización WikiLeaks: en julio de 2010, la organización filtró 92.000 archivos secretos sobre la guerra de Vietnam, y en octubre del mismo año, 391.831 documentos de la guerra de Irak (Figuras 7 y 8 ). La enorme capacidad de almacenamiento solo puede ser apreciada de un solo golpe, gracias a la invisibilidad simultánea de todo lo archivado, al quedar meramente "anunciados" bajo el intervalo que los reúne: los años 2006 a 2010.

Otro ejemplo, acaso más delirante de desmesura, es el servicio que ofrece la compañía Recorded Future (futuro grabado) (Figura 6). Lo que esta empresa promociona es un sistema computacional capaz de analizar, en forma instantánea, 632.115 fuentes abiertas en la web en siete idiomas distintos, con el fin de identificar vulnerabilidades que permitan pronosticar posibles
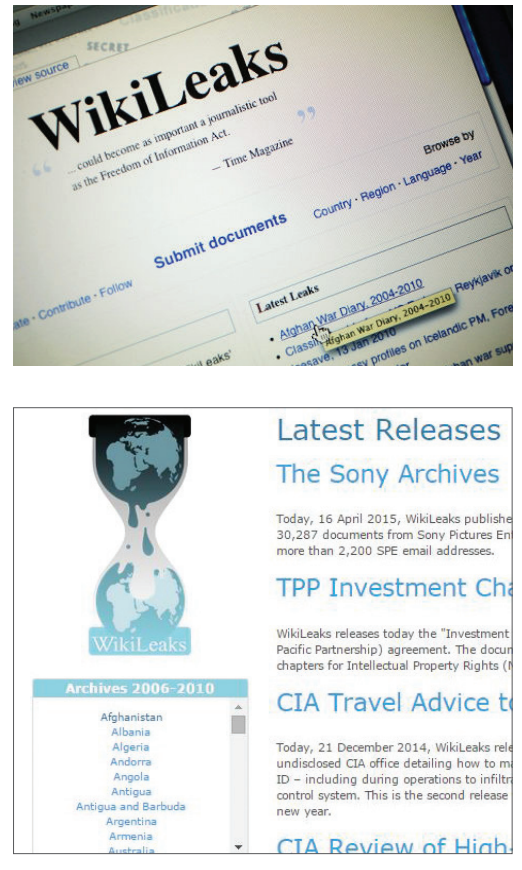

Figura 6. Captura de pantalla desde el sitio web de la compañía Recorded Future Inc. Fuente: <www.recordedfuture.com>.

Figuras 7 y 8 . Capturas de pantalla desde el sitio web de la organización WikiLeaks. 


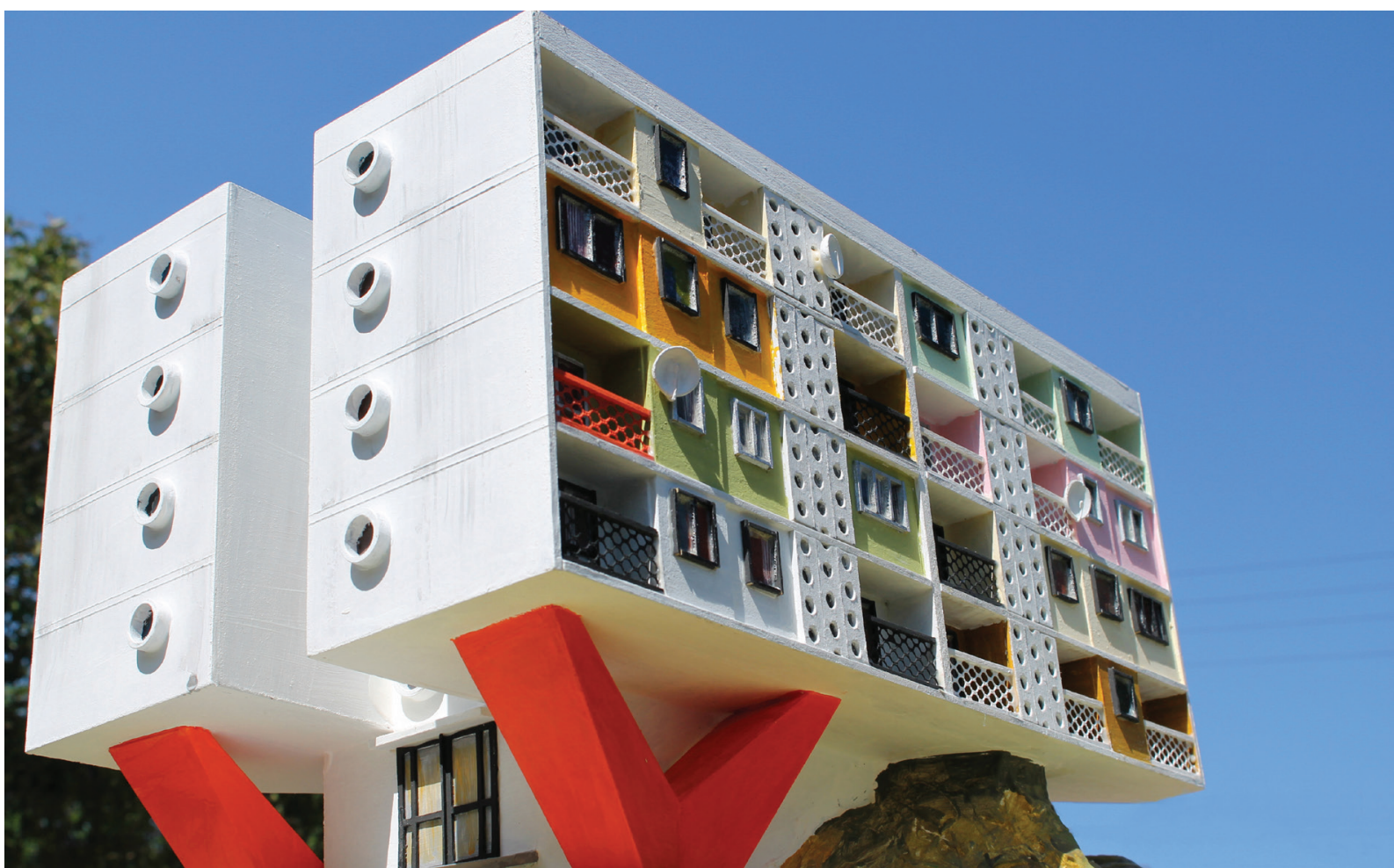

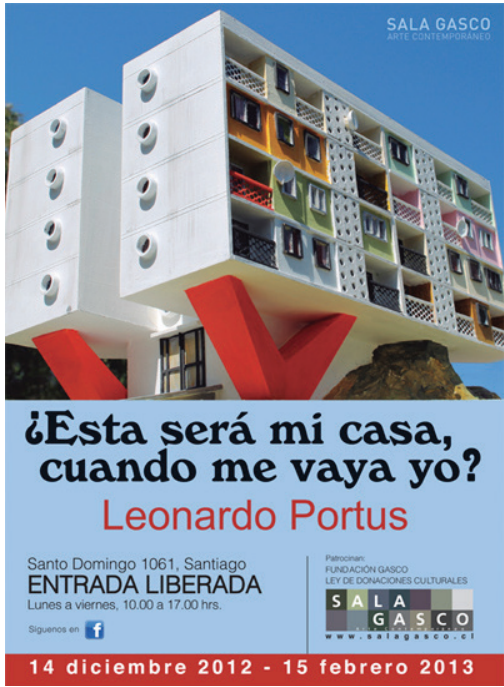

Figura 9. Remodelación Juscelino Kubitschek Valparaíso. Leonardo Portus, exposición ¿Esta será mi casa cuando me vaya yo? Sala Gasco, Santiago de Chile, 2012.

Fuente: Archivo de Leonardo Portus.

Figura 10. Afiche exposición ¿Esta será mi casa cuando me vaya yo? de Leonardo Portus. Sala Gasco, Santiago de Chile, 2012

Fuente: Archivo de Leonardo Portus. y futuras amenazas. Mediante el trabajo de cruce y procesamiento de los datos, es posible arrojar no solo una sino varias "imágenes" del porvenir en materia de seguridad.

Todo lo anterior permite abrir algunas reflexiones en torno al destino que el "mal de archivo" parece reservarnos, sobre todo, si las dirigimos esta vez hacia la noción de proyecto. Lo impresentable que el archivo aloja en su mismo seno y que no es otra cosa que la muerte, amenaza la pertinencia de la propia experiencia testimonial: el testigo parece imposible en Wikileaks por la completa desmesura de lo archivado, como absolutamente superfluo en Recorded Future, a la hora de concebir el porvenir. Ambos casos nos ofrecen una versión deslumbrante de lo que podríamos denominar un "proyecto de archivo". Mientras el primero aspira a convertirse en el mayor depósito de lo inconfesable del poder, el segundo busca pronosticar riesgos inimaginables tras convertir automáticamente en archivos a toda la información de la red. Ahora bien, ante lo desconcertante que puede llegar a significar un "proyecto de archivo" como los mencionados, podríamos reparar en la figura contraria, aunque no menos extravagante, de un "archivo de proyecto". ¿Dónde podemos encontrar desplegada tan insólita intención?, y sobre todo, ¿qué concepción de lo proyectual podría ofrecernos?

Quizás, el trabajo del artista chileno Leonardo Portus puede proporcionarnos un buen ejemplo de un "archivo de proyecto".

Con el nombre de ¿Esta será mi casa cuando me vaya yo?, la obra realizada por el artista en 2013 nos muestra un conjunto de maquetas, fotografías y planos (Portus, 2012) donde ficciona una arquitectura "retro-futurista" (Rosenfeld, 2012, p.2). Por medio de la representación de conjuntos edilicios característicos del modernismo de los 60 y 70 , Portus se pregunta cuál habría sido el destino 

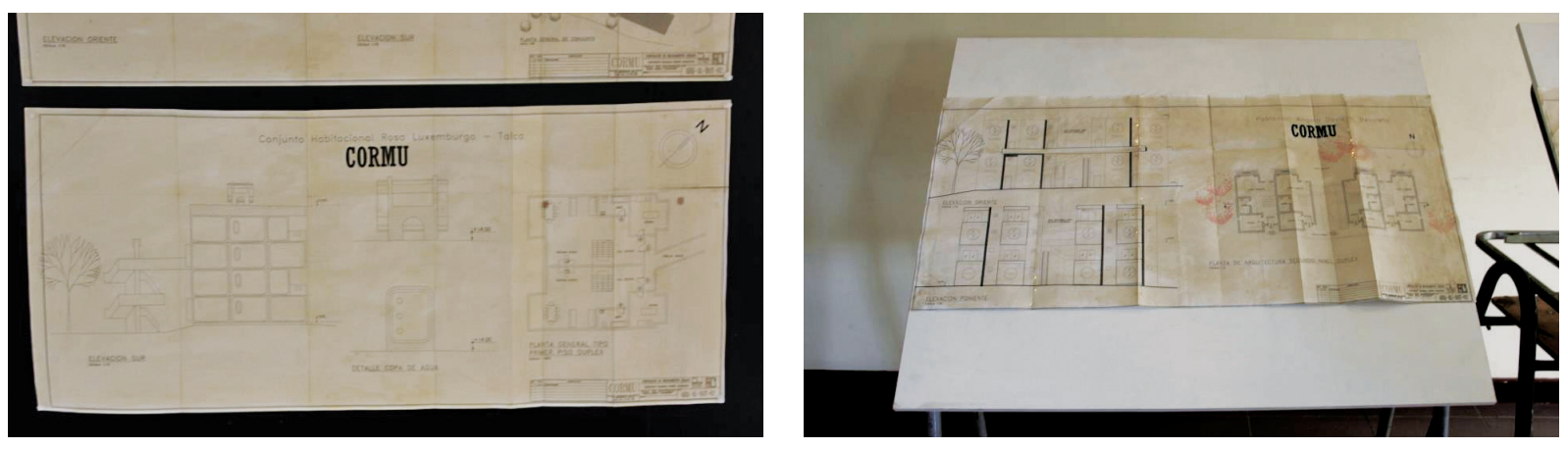

de la arquitectura moderna en Chile, si no hubiese ocurrido el Golpe de Estado. Tomando como referencia el título de una canción de Nino Bravo - muerto en 1973-, el artista intentaba elaborar "una especie de historia alterna o (ucronía)" (Riffo, 2012) que permitiese preguntarnos si realmente estamos en nuestro hogar cuando lo añoramos, si vivimos la verdadera experiencia de habitarlo más en la nostalgia que en la propia realidad (Duque, 2014).

Este cuestionamiento es particularmente importante para pensar la lógica del archivo, puesto que apunta al propio estatuto de la experiencia que, como hemos visto, constituye su núcleo fundamental. Podríamos resumir el cuestionamiento de Portus del siguiente modo: la experiencia concreta del mundo ya no parece posible si por ella entendemos no el puro padecimiento ante lo que acontece en el presente, sino más bien la experiencia del arraigo que el hogar nos entrega. Dicha experiencia, hoy perdida, solo puede recuperarse mediante la nostalgia de una residencia que quiso y no pudo ser, aquella que únicamente la ficción de la obra-archivo, en este caso, nos reporta: el archivo, nos devuelve la experiencia porque alude a la posibilidad del testigo.

Sin embargo, la condición de esa recuperación es enormemente problemática dado que, a diferencia del trabajo de Voluspa Jarpa donde los referentes utilizados han sido verdaderamente extraídos del acopio desclasificado de la $\mathrm{CIA}$, en este caso se trata de una obra donde los archivos son eminentemente ficticios lo que, a su vez, nos convierte en testigos simulados.

En las maquetas, por ejemplo, los proyectos se asoman relucientes, rodeados de una extraña atmósfera de novedad. El paso del tiempo parece no afectar el semblante ideal que los envuelve, salvo por un pequeño e interesante detalle. En una de ellas, en la Remodelación Juscelino Kubitschek, se pueden apreciar en una de sus fachadas la presencia de antenas parabólicas de televisión (Figura 10). Por esta anacrónica presencia, la novedad ideal del proyecto se ve de pronto "arrojada" a la actual contingencia de la globalización, como si el futuro del Movimiento Moderno en Chile, independientemente del Golpe, hubiese terminado igualmente acomodando sus formas colectivas de vida al universo individualizante e hiperconectado del neoliberalismo transnacional. Junto con las maquetas, encontramos también la planimetría (Figuras 11 y 12). Mientras las primeras se esfuerzan por mostrar novedad, los planos, en cambio, ostentan una vetustez que nos regresa a la época en que estos proyectos simulan haber sido ideados. Por medio de un metódico tratamiento de envejecimiento acelerado, esta planimetría pretende mostrarse como una suerte de reliquia testimonial de aquellos proyectos ficticios.

Todo un sistema de índices colabora para dicho efecto: el papel ajado, la manchas, los timbres estatales, así como también los dobleces que buscan
Figuras 11 y 12. Planimetría. Exposición ¿Esta será mi casa cuando me vaya yo? de Leonardo Portus, FAUP Universidad Central, 2013. Fuente: Archivo de Sebastián Alarcón. 
generar la impresión de ser documentos por mucho tiempo guardados. Contrariamente al trabajo museístico o patrimonialista tradicional centrado en sostener el imaginario de los testimonios, está el trabajo archivístico ficcional que Portus nos propone.

Al hacernos transitar desde "imaginario del archivo" - propio de la historiografía o el patrimonio-, al "archivo imaginario", Portus nos obliga a desplazar el problema desde el ámbito epistemológico al eminentemente estético-político. Precisamente en su obra, el archivo es menos un vestigio de lo real que un modus operandi que coloca en primer plano la propia mecánica de la representación archivística.

Podríamos enunciarlo del siguiente modo: eximido de un uso epistemológico, aquel que pretende dar cuenta de lo que "realmente fue", el archivo ficcionado no busca resguardar ni reconstituir lo acontecido sino que, por el contrario, evitar que aquello evocado en él -en este caso, el proyecto moderno- no solo no se convierta en pasado, sino que tampoco se torne presente ni menos futuro. Eso es lo que podría denotar el concepto de "ucronía" -lo sin-tiempo- que Portus nos entrega. La dicotomía entre el relucir atemporal de las maquetas y la vetustez testimonial de la planimetría, hace que la novedad del proyecto - expuesta simbólicamente en las maquetas - sea de algún modo liberada o afirmada a través del archivo imaginario de los planos. En este "archivo de proyecto", el mal de archivo y su comercio con lo que jamás puede presentarse -la muerte-, parece mutar al signo exactamente opuesto: la lucha contra el decaimiento, la facticidad y el tiempo. Precisamente porque su batalla apunta a vencer la finitud, lo que aquí llamaremos "mal de proyecto" nos precave de archivar el futuro bajo una clave progresista que lo conciba como mera prolongación de lo dado. Puesto que constituye lo que hay de impresentable en el proyecto resistiendo toda realización, dicho mal viene a impedir que el presente se clausure, sin más, sobre sí mismo. El "archivo de proyecto", asumido como problemática eminentemente estético-política y no solo epistemológica, permitiría de ese modo acoger su mal: su constitutiva ucronía, lo impresentable que únicamente la obra-archivo está en condiciones de presentar, esto es, el real irrealizable del proyecto.

En efecto, llamaremos "mal de proyecto" a aquella verdad que solamente una consideración ficcional del archivo de proyecto nos permitiría acceder. En un primer sentido, ocupamos este término para enlazar el régimen del proyecto con el concepto de "mal de archivo" que nos propone Derrida (1997). Si para este último el "mal" (del archivo) constituye su inherente propensión de muerte, para el proyecto, en cambio, representa lo contrario: aquello impresentable que no alude al fin (como la muerte), sino a lo ucrónico, a lo incombustible que se resiste a la facticidad y al tiempo.

En una segunda acepción, el "mal” (de proyecto) estaría asociado a lo que el sentido común de los profesionales - del diseño o la arquitectura-, por ejemplo, podrían decretar de un "mal proyecto": aquel que no puede realizarse o que simplemente falla en su concreción por alguna ineficiencia pragmática producto de una errónea ideación. Desde esta perspectiva, el proyecto estaría reducido a la condición de "potencia" cuya plausibilidad -o su "bien" - estaría sujeta a su capacidad de convertirse en "acto". En otras palabras y desde la perspectiva de una virilidad profesional -y por tanto fecundadora-, el "mal" de(I) proyecto sería lo que hay de impotente en él. Esta interpretación nos lleva a desmarcar la noción de proyecto de aquella tradición político-revolucionaria que lo concibe como encarnación de ideales 
o sueños que, de manera latente, descansarían en la situación actual. Bajo esa lectura, el proyecto no sería más que la toma de conciencia de aquellas virtualidades que potencialmente el presente contiene y que aquel está en condiciones de representar imaginariamente, anticipando sinópticamente la obra de la transformación. Las críticas a este modelo se han dejado sentir fuertemente en el pensamiento contemporáneo. En efecto, para el filósofo Alain Badiou, por ejemplo, lo nuevo no es lo que descansa potencialmente en lo viejo, como aquello que permanece virtualmente entre los lindes de lo existente a la espera de un futuro florecimiento. Por el contrario, lo nuevo sería lo que no tiene lugar ni tiempo (en el presente).

Bajo ciertas circunstancias que Badiou denomina "acontecimientos", el régimen que gobierna el presente de todas las cosas, de pronto, es interrumpido por un hecho anormal, absurdo e imposible desde el punto de vista de la lógica que domina el sitio de su aparición. La política como arte de lo imposible, consiste precisamente en volver audible o visible esa anormalidad que el presente impide reconocer. Justamente, el archivo imaginario permite recobrar ese momento impresentable o imposible del proyecto, su mal radical. Lo que debe archivarse no son las huellas de su realización entendidas como testimonios que demuestren su veracidad empírica. Tampoco su apuesta hipotética, pues ello encierra aún el anhelo de comprobación.

Mientras el arte (del archivo) es una intervención que revela el "mal de proyecto" o su condición de imposible-inexistente, la política, sobre los hombros de lo revelado por el arte (del archivo), debe ser quien permita la emergencia del sujeto (o testigo) que pueda operar el paso de lo imposible a lo posible. Pero ello requiere de ciertas precauciones que tanto la historiografía como el pensamiento proyectual deben considerar a la hora de "archivar el futuro".

Primera precaución: evitar una "policía del archivo" que custodie del proyecto únicamente sus realizaciones, o que considere su vocación ficcional solo como una hipótesis a la espera de una efectividad futura.

Segunda precaución: evitar escuchar la seductora voz de la época -la nuestra- que clama por una "ciencia del proyecto". Su demanda ha sido bastante generalizada en el mundo académico del diseño, sobre todo a través del auspicio de las teorías de la complejidad y de sistemas, que domestican lo imposible traduciéndolo a la imagen adecentada del "atractor extraño", la "excepción" o la "incertidumbre", todas ellas deudoras de una ontología política conservadora. Bajo esos términos, una ciencia del proyecto no dejaría otra alternativa para la historiografía que una policía del archivo.

Por el contrario, al igual que el "archivo de proyecto", la mitad del pensamiento proyectual debe estar en el arte, la otra mitad en la política, aunque sin confundirse completamente con ninguna de ellas. Esa parece ser la única alternativa para tornarlo resistente al poder debilitante y aplastante de lo presente, no solo para restituir su plausibilidad histórica, sino que, además, para volver pensable la fecunda extrañeza de su mal. 


\section{Bibliografía}

Adorno, Th. W. (2005). Dialéctica negativa. La jerga de la autenticidad. Madrid: Akal.

Badiou, A. (1990). ¿Se puede pensar la política?. Buenos Aires: Nueva Visión.

Badiou, A. (2009). Compendio de Metapolítica. Buenos Aires: Prometeo.

Badiou, A. (2009). Teoría del Sujeto. Buenos Aires: Prometeo.

Bégout, B. (2001). La potencia discreta de lo cotidiano, Persona y sociedad, $x x I I I(1), 9-20$.

Bégout, B. (2005). La découverte du quotidiene. Paris: Allia.

Blasco Gallardo, J. (2010). Museografiar archivos como una de las malas artes: el indefinido espacio entre el museo, el archivo y la exposición, Errata\#, (1), 147-150.

Bosteels, B. (2010). Lógicas de cambio: de la potencialidad a lo inexistente. En C. Gómez Camarena y A. Uzín Olleros, Badiou fuera de sus límites (pp. 1-30). Buenos Aires: Imago Mundi.

Déotte, J.L. (1998). Catástrofe y olvido. Las ruinas, Europa, el Museo. Santiago de Chile: Editorial Cuarto Propio.

Derrida, J. (1997). Mal de Archivo. Una impresión freudiana. Madrid: Editorial Trotta.

Freud, S. (2001). Obras completas. Buenos Aires: Amorrurtu.

Duque, K. (2012). Exposición: Esta será mi casa cuando me vaya yo. De Leonardo Portus. Plataforma Arquitectura. Recuperado de http://www. plataformaarquitectura.cl/cl/o2-218275/exposicion -esta-sera-mi-casa-cuando-me-vaya-yo-de -leonardo-portus (23 de Enero de 2015).

Heidegger, M. (2002). Sery Tiempo. Santiago de Chile: Editorial Universitaria.

Heidegger, M. (1996). Qué es metafísica y otros ensayos. Buenos Aires: Ediciones Fausto.

Hegel, G. W. F. (1989). Estética. Barcelona: Península.

Jencks, C. (1986). El lenguaje de la arquitectura posmoderna. Barcelona: Gustavo Gili.

Lacan, J. (2003). El seminario VII: la ética del psicoanálisis. Buenos Aires: Paidós.

Levinas, E. (2001). Algunas reflexiones sobre la filosofía del hitlerismo. Buenos Aires: Fondo de Cultura Económica.

Levinas, E. (1981). De l'existence à l'existant. Paris: Vrin.

Madrid, A. (2012). Leonardo Portus. Plan Nacional de Vivienda. En L. Portus, ¿Esta será mi casa cuando me vaya yo?. [¿Esta será mi casa cuando me vaya yo?] Sala Gasco, Santiago de Chile, 13 de Diciembre de 2012 - 15 de Febrero de 2013.

Marx, K. (2005). Contribución a la crítica de la economía política. México: Siglo XXI.

Michaud, I. (2007). El arte en estado gaseoso. México: Fondo de Cultura Económica.

Nietzsche, F. (2000). De la utilidad y los inconvenientes de los estudios históricos para la vida. Madrid: Edaf.

Nietzsche, F. (1994). Sobre verdad y mentira en sentido extramoral. Madrid: Tecnos.

Portus, L. (2012). ¿Esta será mi casa cuando me vaya yo?. [¿Esta será mi casa cuando me vaya yo?] Sala Gasco, Santiago de Chile, 13 de Diciembre de 2012 - 15 de Febrero de 2013.

Recalcati, M. et al. (2006). Las tres estéticas de Lacan (psicoanálisis y arte). Buenos Aires: Ediciones del Cifrado.

Recorded Future: Real-Time Threat Intelligence. Recuperado de https://www.recordedfuture.com (23 de Enero de 2015).

Riffo, S. (2012). “¿Esta será mi casa, cuando me vaya yo?” de Leonardo Portus en la Sala Gasco. mich. Recuperado de http://www.museointernacionaldechile.cl/esta-sera-mi-casa-cuando-me-vaya-yo-de-leonardo-portusen-la-sala-gasco/ (23 de Enero de 2015).

Rojas, S. (2012). El arte agotado. Santiago de Chile: Sangría Editorial.

Rosenfeld, D. (2012). Presentación. En L. Portus, ¿Esta será mi casa cuando me vaya yo?. [¿Esta será mi casa cuando me vaya yo?] Sala Gasco, Santiago de Chile, 13 de Diciembre de 2012 - 15 de Febrero de 2013.

WikiLeaks. Recuperado de https://wikileaks.org (23 de Enero de 2015).

Žižek, S. (2007). El espinoso sujeto. El centro ausente de la ontología política. Buenos Aires: Paidós.

Žižek, S. (2009). El sublime objeto de la ideología. Buenos Aires: Siglo Veintiuno Editores. 